\title{
Continuity and Mathematical Ontology in Aristotle
}

\author{
Keren Wilson Shatalov
}

In this paper I argue that Aristotle's understanding of mathematical continuity constrains the mathematical ontology he can consistently hold. On my reading, Aristotle can only be a mathematical abstractionist of a certain sort. To show this, I first present an analysis of Aristotle's notion of continuity by bringing together texts from his Metaphysica and Physica, to show that continuity is, for Aristotle, a certain kind of per se unity, and that upon this rests his distinction between continuity and contiguity. Next I argue briefly that Aristotle intends for his discussion of continuity to apply to pure mathematical objects such as lines and figures, as well as to extended bodies. I show that this leads him to a difficulty, for it does not at first appear that the distinction between continuity and contiguity can be preserved for abstract mathematicals. Finally, I present a solution according to which Aristotle's understanding of continuity can only be saved if he holds a certain kind of mathematical ontology.

My topic in this paper is Aristotle's understanding of mathematical continuity. While the idea that continua are composed of infinitely many points is the present day orthodoxy, the Aristotelian understanding of continua as non-punctiform and infinitely divisible was the reigning theory for much of the history of western mathematics, and there is renewed interest in it from current mathematicians and philosophers of mathematics. Stewart Shapiro, Geoffrey Hellman, and Oystein Linnebo ${ }^{1}$, for example, are together working on a project which uses contemporary mathematical and logical tools to develop a mathematics of continuity which preserves the Aristotelian intuition and which is equivalent, at least in part, to the analysis account of continuity as punctiform.

My project began as an examination of the disagreement between Aristotle and the atomists which was aimed at meditating on the merits of the Aristotelian intuition as it appears in Aristotle. Thus much of this paper consists in an exegesis of Aristotle's

${ }^{1}$ Cf. "Aristotelian Continua." Philosophia Mathematica, Volume 24, Issue 2, 1 June 2016, Pages 214-246, and "Frege Meets Aristotle." Philosophia Mathematica, Volume 25, Issue 1, 1 February 2017, Pages 73-90. 
understanding of the mathematical notion of continuity. In examining Aristotle's views about continuity, however, I was led to the somewhat surprising conclusion that Aristotle's particular way of accounting for the non-punctiform nature of continuity cannot be separated from his mathematical ontology. First, I came to think that there is good reason to hold that Aristotle is offering an analysis of continuity, and a distinction between continuity and contiguity, which is intended to apply both to bodies and to abstract mathematical items such as straight lines. I will offer some defense of this in the body of the paper. Furthermore, I found that this raises an interesting puzzle, whose solution has bearing on what kind of mathematical ontology Aristotle can consistently offer.

The puzzle is that Aristotle's analysis of continuity does not at first seem to work equally well for both sensible bodies and abstract mathematicals. This is no surprise for a commentator who holds that Aristotle's continuity applies only to physical bodies, but given my reasons for thinking that Aristotle had in mind also abstract mathematical items, if unsolved this problem seems a weakness in his account. I argue that if Aristotle accepts or has in mind the solution I offer him, he can only consistently hold a version of mathematical abstractionism which allows that mathematical objects exist in the empirical world in a dependent sort of way by being instantiated in bodies. I do not take this to imply that Aristotle is a strict literalist about mathematical ontology. Rather, I think that this implies that Aristotle is, or can only consistently be, a mathematical abstractionist of a certain kind. That is to say, if I am right about how Aristotle understands continuity, then this provides support for a line of interpretation of Aristotle mathematical ontology. I will argue that the mathematical ontologies ascribed to Aristotle by Mueller (1970) and Annas (1976) cannot solve the problem. On the other hand, I argue that Corkum (2012) and Lear (1982) offer readings of Aristotle's understanding of mathematical abstraction which, while differing from each other in certain significant respects, are both consistent with my reading of Aristotle on continuity and contiguity.

\section{$\S 1$ Two kinds of continuity: [relational] and [nonrelational]continuity}

For Aristotle, as for anyone, contiguity is a relation. On the other hand, unlike most

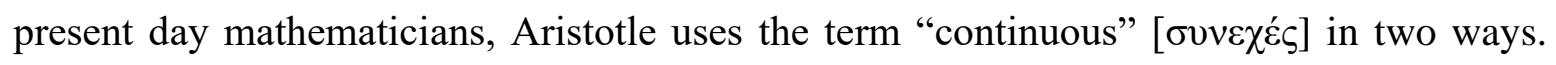


Sometimes, as for example in the first lines of Physica VI.1, he uses the term "continuous" in a relational sense: at 231a21-23 Aristotle says that two magnitudes ${ }^{2}$ stand in a relation of continuity when the extremities at which they touch are one. In the next line, by contrast, Aristotle indicates that it follows from this that "nothing that is continuous can be composed of indivisibles: e.g. a line cannot be composed of points" (231a24-25). ${ }^{3}$ Here, evidently, Aristotle uses the term "continuous" to refer to a property which belongs to a single magnitude. For a further evidence that Aristotle sometimes treats of a relation of being continuous, and sometimes of a property, the following texts may be consulted. At 227a10, 227a21, 231a30, and 231b1-5, Aristotle discusses the relation of continuity. In fact, at 227a1 he categorizes it as a species of contiguity, a special case of touching. At 227a13-15, and 231b11-12 and in Metaphysica V.6, on the other hand, Aristotle clearly has in mind a property. A present-day mathematician thinks of continuity only as a property. Aristotle's ambiguous use of the term thus marks a departure from present-day usage, one which, I think, points toward the understanding of whole and part which is key for Aristotelian continuity.

It would be too uncharitable to attribute to Aristotle the mistake of failing to notice the difference between properties and relations, especially since this is something to which Aristotle gives explicit attention in his corpus (e.g., Categoriae 7). Rather, I think that

\footnotetext{
${ }^{2}$ By "magnitude" in this paper I mean "a sized thing," that is to say, any spatially extended item. I use the term "magnitude" here in part because, as part of its inheritance from the Latin magnitudo,

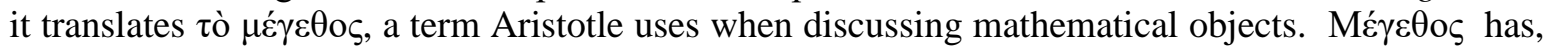
in Greek, many of the same uses as "magnitude" in English or the Latin magnitudo; it means greatness, largeness, or size. In the passages of interest in this paper, Aristotle uses the term to refer to the genus of mathematical object of which lines, figures, and solids are species (e.g. Physica 231b21-25, Metaphysica 1077a9-14). It contrasts with à $1 \theta \mu$ ós, or number, and in general with discrete or non-continuous mathematical objects. This differs somewhat from the usage of other

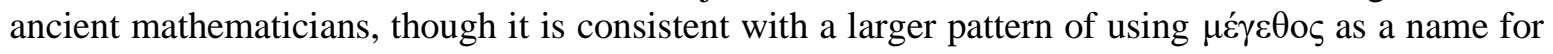
mathematical objects. Compare, for example, Euclid's use of the term in book V of Elements, according to which a number as well as a line counts as a $\mu \varepsilon \dot{\varepsilon} \varepsilon \theta 0 s)$. Thus, following Aristotle, in this paper I will use "magnitude" to refer to spatially extended items. A line is a magnitude, insofar as it is an item having some length, and a square and a cube are also magnitudes. Similarly, any physical body is a magnitude insofar as it has height, depth, and width. Thus the term "magnitude" is useful insofar as it is applicable both to pure or abstract geometrical items such as lines and to physical, measurable bodies. I will call abstract mathematical objects such as lines "pure magnitudes", and sensible, sized bodies "sensible magnitudes", where a distinction is called for.

${ }^{3}$ Unless otherwise indicated, in what follows all translations will be from the R.P. Hardie and R.K. Gaye translations of Physica and Metaphysica in The Complete Works of Aristotle Vol I\&II, ed. Jonathan Barnes, Princeton, Princeton University Press (1984).
} 
attending to Aristotle's use of the term "continuous" shows that Aristotle has in mind two kinds of continuity: one a relation, the other a property. The difficulty for his readers is that both when he refers to the relation and when he discusses the non-relational property Aristotle appeals to the same definition of things being continuous, the one given at 227a10-12.

Nevertheless, however confusingly Aristotle seems to conflate these two, a consistent position can be pieced together. A comparison of the Physica passage with the discussion of unity in Aristotle's Metaphysica, especially Metaphysica V, shows that nonrelational or holistic continuity is a kind of per se unity; all continua are per se unities. ${ }^{4}$ Further, something is [non-relational] continuous when the boundaries of its successive parts not only touch but become one, i.e., when its parts are [relational] continuous with each other. ${ }^{5}$ This is what Aristotle has in mind when he claims at 227a13-15 that "This definition [the definition of continuity] makes it plain that continuity belongs to things that naturally in virtue of their mutual contact form a unity".

This description of continua might seem paradoxical. In allowing that a continuum results when multiple magnitudes are [relational] continuous, Aristotle seems to admit two inconsistent descriptions of the same case. On the one hand there seems to be only one magnitude, one continuum. On the other hand Aristotle allows that there are two magnitudes which are continuous with each other. Aristotle has in mind here what are sometimes awkwardly labeled "potential parts" to show that there is no contradiction involved in allowing that a continuum is in a way one, and in a way many. ${ }^{6}$ According to

${ }^{4} \mathrm{I}$ do not mean to imply that the reverse is also true; not all per se unities are continua. For example, the divine being from the final books of Aristotle's Physica and Metaphysica is a per se unity. However, being simple, Aristotle's god is not a mathematical continuum. Continua are per se unities which have parts of a certain kind.

${ }^{5}$ Bostock, in his (1991) "Aristotle on Continuity in Physica VI" points out these two uses of the term by Aristotle, and concludes as well that for Aristotle a continuum (something which is what I am calling [non-relational] continuous) is such that its parts are what I am calling [relational] continuous. However, he thinks that Aristotle only explicitly defines [relational] continuity. Further, he argues that the implied definition of [non-relational] continuity is problematic. I think that he overlooks the kind of unity which a continuum is supposed to have, and thus the kind of unity which [relational] continuity provides. For this reason he does not see how the definition Aristotle offers can apply to both kinds of continuity.

${ }^{6}$ Compare Aristotle's response to Parmenides' claim that what-is is one and continuous in Physica I.2. At 185b9-10 Aristotle says of the monists that "If their One is one in the sense of continuous, it is many; for the continuous is divisible ad infinitum". He goes on to say that "On this point indeed 
this special kind of parthood (this is not the only kind of parthood Aristotle allows into his mereology), a part of a continuum is something which is potentially a distinct object, i.e., something which is separable but not yet separated. Continua are per se unities which are in a way one (they are actually one), but which are also in a way many, since they have parts which are potentially distinct objects of the same kind. The multitude represented in their parts does not compromise the per se unity of the whole precisely because the parts are [relational] continuous, and this means that they are merely potential.

This can be clarified by turning to Aristotle's Metaphysica. In Metaphysica V Aristotle distinguishes several ways in which something can be one. The first two ways are relevant here:

We call one (1) that which is one by accident, (2) that which is one by its own nature. <...> Of things that are called one in virtue of their own nature some $(a)$ are so called because they are continuous, e.g., a bundle is made one by a band, and pieces of wood are made one by glue. <...> Those things are continuous by their own nature which are one not merely by contact; for if you put pieces of wood touching one another, you will not say these are one piece of wood or one body or one continuum of any other sort. Things, then, that are continuous in any way are called one." $(1016 \mathrm{a} 1,5,7-9)^{7}$

What is translated here at $1016 \mathrm{a} 1$ as something being one 'by its own nature' rather than accidentally is the Greek phrase $\kappa \alpha \theta$ ' $\alpha$ ió, of which the Latin per se is a literal translation. Since it is also a more widely used expression, I will depend upon it here. Aristotle's claim in this passage is that things which are continuous are, in virtue of being

they were already getting into difficulties and admitted that the one was many - as if there was any difficulty about the same thing being both one and many, provided that these are not opposites; for what is one may be either potentially one or actually one" (186a1-3). Aristotle seems happy to allow that the same thing can be both one and many, which, I think, undermines the strict requirements for a continuum's unity David Furley presents in his (1982). Furley argues that we cannot say, on Aristotle's account, that the line from Trenton to New York passes through Princeton Junction for "[T]he mention of Princeton Junction actualizes the intermediate point and thus transforms continuity into contact" (Furley, pg. 24). He worries that a continuous line can no longer be continuous "as soon as an intermediate point is mentioned or even considered" (pg. 23) because it is no longer one, and argues that this fits with Aristotle's treatment of the definitions of "continuous" and "touching" in Physica V, as well as his treatment of potential divisions in Physica VIII.8. Yet in Phys. I.2 Aristotle seems to think that no difficulty arises for the unity of a continuum when its parts are distinguished from each other, as long as the parts are still understood to be merely potential; this way, the continuum is actually one and only potentially many, and there is no conflict. Furley seems to make it impossible for someone to consistently think of something as potentially many and actually one, for even to consider a division actualizes the same.

7 Trans. W.D. Ross, in Vol. II of The Complete Works of Aristotle. 
continuous and thus in virtue of themselves, or per se, unified wholes. Continua, that is to say, things which are [non-relational] continuous, are per se unities, for continuity is a way of being per se one. Aristotle also says in the surrounding passage from Metaphysica that among continuous things some are continuous by nature [ $\tau \tilde{n} \varphi v ́ \sigma \varepsilon 1]$ and some by art

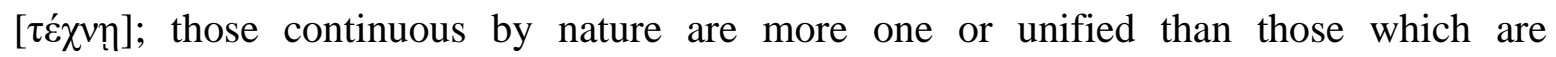
continuous by art (1016a4). Though Aristotle does not explicitly claim in the Physica passages that [non-relational] continua are $\kappa \alpha \theta^{\prime}$ avió unities, he does claim that they are instances of $\sigma 0 ́ \mu \varphi v \sigma r \varsigma$, a natural joining together, at 227a23-27. ${ }^{8}$ I take this to mean that such continua are naturally one, and thus to be consistent with the Metaphysica thesis that they are per se unities. ${ }^{9}$

The difference between per se unity and accidental unity is best illustrated by examples. Examples of accidental unities are such as piles of sand, stacks of wood, or handfuls of straw. Intuitively these are not really one; they are multitudes of grains of sand or pieces of straw, etc. In some contexts it might still be useful to think of many things together as being one. In this way I can refer to and think of something as "pile of straw," and I can distinguish it from some other pile of straw. But what I refer to when I speak this way is still a stack or a heap - a bunch of independent things which happen to be put together. Their unity, such as it is, does not belong to them in themselves, but is a feature of the way I think of them and name them.

Continuing the example, what would it take to make the pile of straw a whole? Binding or gluing the sticks of straw together (1015b36). Then instead of a heap of individual sticks of straw, there would be a single thing whose unity is not just a matter of proximity: the head of a broom. A sign of its unity is that the whole thing will now move together. Aristotle offers as an additional example of something which is continuous a

\footnotetext{
${ }^{8}$ Sylvia Berryman points out that, while Eudemus seems to have distinguished being continuous from being a natural joining together, a бó $\mu \varphi v \varepsilon \varsigma$, Wehrli uses passages from Physica to show that Aristotle treats $\sigma u ́ \mu \varphi v \varepsilon \varsigma$ as a synonym of $\sigma u ́ v \varepsilon \chi \varepsilon \varsigma$ in the Physica discussion of continuity (Berryman, pg. 157-158).

${ }^{9}$ As further support for the claim that in Physica Aristotle views continuity as a species of unity, note that Furley (1982) and Berryman (2002) suggest that in Physica V.3 Aristotle introduces the definitions of things being in contact, in succession, contiguous, and continuous as being along a scale from less to more unified (Furley, pg. 24-25; Berryman, pg. 159).
} 
spoken or sounded syllable. ${ }^{10}$ A syllable, he says, is more than its component parts. The syllable "ba" has the component parts of b and a. But it is not merely b+a, for then "ba" and "ab" would be the same syllable. (1041b11) In the case of both the straw and the syllable, contact or grouping of the parts is not sufficient to produce a continuous whole. Something more is required to bind them or unify them. For Aristotle, this something more is not another element in the compound. In the way Aristotle is thinking, the order of the parts of the syllable and the glue in the head of the broom are not parts in the same way as the letters or the straw. Nevertheless, the glue and the order of the letters are what enable the broomhead and syllable, respectively, to hold themselves together as one.

The idea is that things which are [non-relational] continuous in some sense hold themselves together, while magnitudes which are contiguous with each other are not similarly responsible for their being together. There is an interesting way in which this comparison is exhibited by the etymology of the Greek words. The Greek word for contiguous is $\dot{\varepsilon} \chi o$ ó $\varepsilon v 0 v$; the word for continuous is $\sigma v v \varepsilon \chi \varepsilon \dot{\varepsilon}$. Both of these come from the same root, the verb $\varepsilon^{\prime} \chi \omega$, which means, roughly, to have or hold in hand. $\dot{\chi} \chi$ ó $\mu \varepsilon v o v$ is the

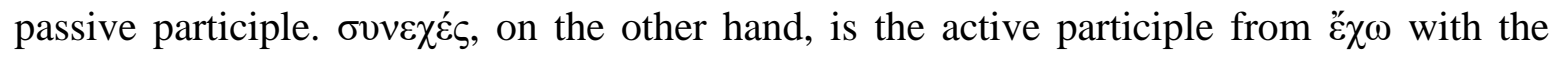
prefix $\sigma v v$, which means "with" or "together." A $\sigma v v \varepsilon \chi \varepsilon \dot{\zeta} \zeta$ or continuous thing is something which holds together. Cornford notes the same thing in a footnote to the Greek text in the Loeb edition of the Physica. Comparing the Greek etymology of $\sigma u v \varepsilon \chi \varepsilon \dot{\varepsilon} \varsigma$ to the Latin etymology of "continuous," he says the following:

$C f$. continent $=$ continuous land unparted by sea, a 'continent' person, one who can 'hold himself together.' In Greek and Latin the etymological implication of the phrase is more general and obvious than in English. (pg. 38, footnote b)

This comes through in the Physica V\&VI discussion. Aristotle begins his exposition of continuity at $227 \mathrm{a} 9$ explaining that "A thing that is in succession and touches [ä $\pi \tau \eta \tau \alpha l]$

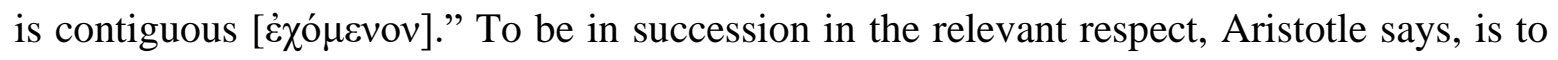

\footnotetext{
${ }^{10}$ Note that in Categoriae at $4 \mathrm{~b} 22$ Aristotle mentions language as an example of a discrete, rather than a continuous quantity. The apparent conflict between this and the Metaphysica passage can be resolved by noting that in Categoriae Aristotle argues that language is discrete by noting that the syllables do not have a common boundary with each other. This is consistent with the definitions of contiguity and continuity offered in Physica V \& VI. But in the example from his Metaphysica Aristotle is not interested in the way in which one syllable is bound to another syllable, but rather in the way in which each syllable itself stands as a unity.
} 
be after something else such that nothing else of the same kind is between the thing and what precedes it (226b35). For example, next door houses on a neighborhood street are in succession in this way, for even though there are grassy lawns between them there are no houses between them. They are in succession but not contiguous. For something to touch $[\ddot{\alpha} \pi \tau \omega]$ another is for its boundary to be together in place with the boundary of the thing it touches (226b20). ${ }^{11}$ Thus next door apartments, though not next door neighboring houses, are contiguous, since they are in succession and their boundaries touch.

Aristotle's complete definition of the continuous is as follows:

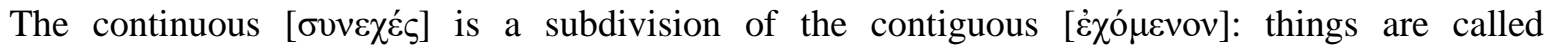
continuous when the touching [ä $\pi \tau o v \tau \alpha l]$ limits of each become one and the same and are (as the

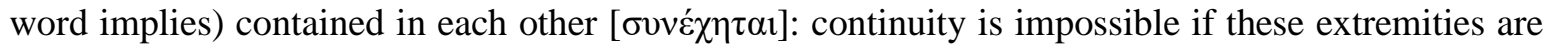
two. $(227 \mathrm{a} 10-13)$

Magnitudes are contiguous when their boundaries are together in place, or touch; they are continuous when they not only touch but their boundaries where they touch become one.

Given that Aristotle presents continuity as a species of contiguity, a brief note on my subsequent use of the term "contiguous" in this paper is in order. In this paper I am concerned with these two species of the contiguous, the merely contiguous and the continuous. For the rest of the paper I will use the term "contiguous" to refer to the merely contiguous, when the boundaries of two magnitudes touch but do not become one.

Let us return to the passage from Physica. Having claimed that something is not a continuum if the boundaries of the parts are two and not one, Aristotle goes on to say that "[T] $]$ his definition makes it plain that continuity belongs to things that naturally in virtue of their mutual contact form a unity. And in whatever way that which holds them together is

${ }^{11}$ Aristotle clarifies that by "together" with respect to place he means "in the same primary place" (226b21-22). This is a notably problematic clarification if it is taken strictly (cf. Furley's and Miller's contributions to Infinity and Continuity in Ancient and Medieval Thought) Aristotle defines primary place as the innermost boundary of the containing body (212a20). Strictly speaking, points thus cannot be in place. Aristotle usually seems loathe to claim that they are; e.g., at 212b24, where he says that "There is no necessity $\langle\ldots\rangle$ that a point should have a place," following which he argues that only moveable bodies are in place (212b29). Difficulties about Aristotle's account of place are too tangled and written-over to be entered into in this paper, however. Further, if we take him not to be speaking strictly about place in this passage, I think that the sort of thing Aristotle is gesturing at when he says that boundaries are together in place is clear enough for the present project. 
one, so too will the whole be one, e.g. by a rivet or glue or contact or organic union" (227a15).

The translation just quoted may be misleading. The idea that the parts touching each other ("mutual contact") is sufficient to unify them as a continuum seems to elide the very distinction between the continuous and the contiguous for which Aristotle is arguing. But it need not. When at 227a9 Aristotle defines a contiguous magnitude as one which "touches"

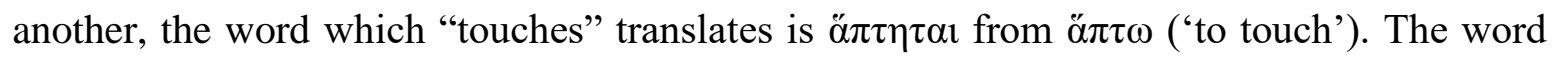

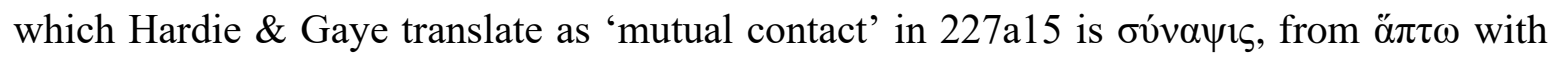
the prefix $\sigma v v$. While literally a $\sigma v ́ v a \psi i s$ is a touching-together, or a mutual contact, the verb бuvá $\pi \omega$, from which the noun is derived, usually means something a bit stronger. The Liddell and Scott lexicon offers as its first meaning "to join together," or "to bind". The parts do not form a continuum merely by touching or being contiguous. Instead, it is by the joining or binding of what was before merely contiguous that a continuum arises. The use

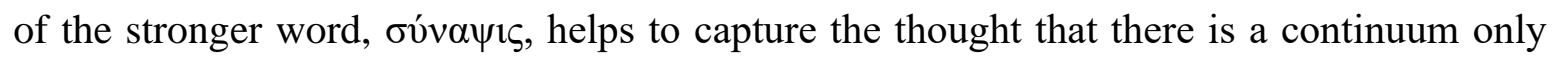
when the boundaries of the parts do not merely touch but become one in such a way that the magnitudes together form a unity.

The consideration of continua as per se unities prepares the way for the idea of potential parts. The expression "potential parts" is somewhat misleading, though as it has been used in the context of this and related issues, I make use of it again here. The slogan for potential parts is straightforward enough: "things that are thus actually two are never actually one" (1039a3). But something can be actually one and potentially two (cf. Physica I.2 186a1-3). This is the case for continua. Continua have parts by having in them items whose parthood consists in their possibly being distinct and separated items. For example, a line 10 centimeters in length has parts in the sense that it is possible for it to be dissolved into two lines, each 5 centimeters long. A pie has a part in the sense that possibly a distinct item, a slice, could be separated from it. The pie and the line are each actually one, but potentially many. The parts of continua such as the line and the pie are parts by being separable, not separated. Thus on Aristotle's understanding, the parthood relation which the parts of continua have must be understood modally.

An argument that continua such as are proposed in Physica V \&VI can only have parts in this modal kind of parthood can be developed by analogy with an argument 
Aristotle offers in 1039a3-10. There he argues that if the parts of substances are also substances, then those parts can exist only potentially. Replacing "substances" with "continua", I think we can see why the parts of Aristotelian continua cannot be contiguous with each other. The argument is as follows. Heaps or piles of things are actually, in virtue of themselves, multitudes ${ }^{12}$; it is only accidentally that they are one. But continua, especially things which are per se continuous (1016a4), are actually, in virtue of themselves, unities. Furthermore, the parts of continua also have the property of continuity, since lines are non-punctiform and infinitely divisible. Thus the parts of continua are also per se unities. If the parts are actual then continua are both actually one and actually many. Thus continua must have parts only potentially. ${ }^{13}$ This sort of reasoning also helps to show why the parts of continua are [relational] continuous with each other.

It must be noted that in the above argument I rely as a premise upon the claim that continua are infinitely divisible. I take this to follow from Aristotle's definition of continuity, and to be an essential part of his understanding of it, though it is not the focus of my essay here. Yet David Bostock, in his "Aristotle on Continuity in Physica VI"14 argues that it does not follow (Space, Time, Matter, and Form, pg. 162). One reason for this is that Bostock takes Aristotle's definition to be left implicit in the text in Physica VI, so that it must be teased out by examining what underlies the claims Aristotle makes about it. The definition Bostock offers on behalf of Aristotle is as follows: "a continuum is anything which (i) can be divided into two parts, and (ii) is such that any two parts into which it is divided must share a limit" (pg. 162). Apart from the emphasis on the kind of whole or unity that the two parts form, significant though I take this to be, Bostock's definition is much the same as the definition which I found in 2271a10-13, as quoted above. Bostock thinks that it does not follow from this definition that the parts of continua are further divisible for the following reason:

\footnotetext{
${ }^{12}$ Aggregative wholes, such as piles or sets or groups of things, can have parts which bear towards the wholes of which they are parts a different kind of parthood relation than the parts of per se unities such as continua.

${ }^{13} C f$. also the argument that the parts of living things and souls can only exist potentially, since living things and souls are "one and continuous by nature" (1040b5-15).

14 "Aristotle on Continuity in Physica VI", Space, Time, Matter, and Form: Essays on Aristotle's Physica. Oxford University Press (2006): 158-188.
} 
Suppose we take a finite line, and suggest 'dividing' it into these two parts: one part is to be an endpoint of the line, and the other part is to be all the rest of the line, excluding this end-point. (Thus the second part is what we call a 'half-open' interval, containing all the points of the line except this one end-point,) Now we may surely assume that a finite line is a continuum, if anything is, so if Aristotle's definition is correct then the two parts into which we have divided it must share a limit. According to one of Aristotle's lines of thought, they do not, since he claims that a point has no limit. But in that case we must simply reject the definition as incorrect. (pg. 162)

Bostock throws Aristotle a bone by suggesting that he take the point to be its own limit (ibid). This allows that the two "parts" of the continuum, the point and the half-open interval, share a limit, namely, the point itself. Since according to Aristotle the point is not divisible, however, Bostock argues it is consistent with the proposed definition of continuity that that parts of continua are not all further divisible.

Bostock suggests that one way to rebut this rejection is to "put some restrictions on what is to count as a 'division' so that the example we have considered does not qualify." (pg. 163) And indeed I wish to so object. Bostock offers as a possible Aristotelian restriction that "any way of dividing the line into any number of parts - finite or infinitemust yield parts that share limits" (ibid). Yet he rejects this proposed principle as unreasonable in its own right.

I do not think Aristotle needs to take on such a premise as Bostock offers him to avoid Bostock's objection; he already has reason to reject Bostock's proposed counterexample from his understanding of points. According to Aristotle, points are the extremities or boundaries of line segments. (Categoriae 5a $2^{15}$; cf. Euclid's Elements, Book I def. 3). As boundaries or limits, they are dependent sorts of beings (Metaphysica XI.1060b12-19). They are always the boundaries of something else, in that they depend for their existence on whatever they bound. Michael White has put it this way: "Aristotle's conception of points is 'constructive' in the sense that they are always conceived in terms of continuous magnitudes, rather than vice versa" (Continuous and Discrete, pg. 12). ${ }^{16}$ Fred Miller, similarly: "For an actually existing point necessarily presupposes the existence of

\footnotetext{
${ }^{15}$ In The Complete Works of Aristotle, vol. I.

16 Michael White. The Continuous and the Discrete: Ancient Physical Theories from a Contemporary Perspective. Oxford: Clarendon Press, 1992.
} 
extended magnitudes <...>” (“Aristotle Against the Atomists," pg. 100). ${ }^{17}$ Thus there are no points which stand alone or are not the limits of lines, and, further, no lines which do not have points as their limits. Because of this, for Aristotle, all lines are what a modern-day mathematician would call closed intervals. Points, since they are boundaries, are not parts of lines in the same way that line segments are parts of lines, for they cannot stand alone, and result secondarily from the division of one line into two or more. ${ }^{18}{ }^{19}$ In other words, because of the way Aristotle understands points as boundaries or limits, Bostock's counterexample fails. Further it is thus a consequence of Aristotle's views about points as limits, in conjunction with his definition of continuity, that any way of dividing a line yields parts that share limits, rather than a principle of division of continua which must be assumed.

Thus, for Aristotle, [non-relational] continua are per se unities which have parts which do not overlap, and which are such that if they were actually divided they would be separate per se unities with the same sort of ontological status as the original line. Inasmuch as the potential parts share boundaries, they are like the sticks of straw which are bound together to form the head of the broom; they form a unity. Yet since they could stand on their own if their bond were to be broken, that is, if they are no longer holding together

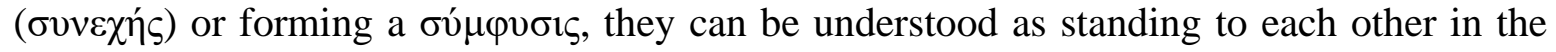
relation of continuity. This understanding of continuity is also closely related to Aristotle's understanding of contiguity. A continuous whole, whether a body or a purely geometrical item, is an undivided per se unity which has parts only potentially. Its parts are such that

${ }^{17}$ F. D. Miller, Jr. "Aristotle Against the Atomists", in Infinity and Continuity in Ancient and Medieval Thought, Ed. N. Kretzmann. Ithaca, N.Y., and London: Cornell University Press, 1982

${ }^{18}$ A similar point can be made, mutatis mutandis, about lines as the boundaries of figures.

${ }^{19}$ Another way of seeing that line segments and points cannot be parts of lines in the same way is to note, as Michael White does, that "the 'addition' or 'subtraction' of points considered as limits of continuous parts of a continuous whole does not affect the quantity or measure of the sum of the measure of the parts versus the measure of the whole; that is, when we divide a continuous whole we gain an additional point (the potential single point of division has become two points, the respective limits of the two pieces), but the measure of the whole is no less than the sum of the measures of the parts" (The Continuous and the Discrete, pg. 13). In his book, White emphasizes the role of process in Aristotle's thought about continuity; roughly, continua are infinitely divisible in the sense that there is some process of division which could be repeated infinitely. The lack of process in the generation of points from lines, or lines from figures (when one divides a figure one produces other figures and, incidentally, therefore also lines), underscores both their dependent nature and their different relation to the whole than the proper parts which they define. 
their boundaries have become one, no longer actually but only potentially distinguishing them; they are continuous with each other. Nevertheless, if the parts are made actual, the continuum being destroyed, the parts would be actually numerically distinct magnitudes, marked off from each other by their erstwhile shared boundary. Thus a continuum is such that when successive parts are actualized they bear toward each other the relation of contiguity.

\section{$\$ 2$ The continuity of abstract and physical magnitudes}

In my view Aristotle means for his account of continuity and of contiguity to apply both to pure and to sensible magnitudes, that is, both to abstract mathematicals and to bodies. It might be argued against me that Aristotle only meant it to apply to sensible magnitudes. After all, Physica is not a mathematical treatise, and the discussion of continuity and contiguity itself comes as part of a long inquiry into change, which is directed towards understanding natural substances as changing things. However, the properties which Aristotle ascribes to continuous bodies or things in the Physica $\mathrm{V}$ passage are exactly the ones he makes use of to argue in the very next book of Physica that lines, in particular, cannot be composed of points. There he is arguing that no continuous thing can be composed of indivisibles, and he does so by taking lines and points as examples of continua and indivisibles, respectively. He seems to have in mind here abstract geometrical items, or pure magnitudes; elsewhere he suggests that no physical bodies contain mathematical lines and points (cf. Metaphysica III.1002a15-19). ${ }^{20}$ Earlier in Physica (Physica II.2.192b24-194a27) Aristotle distinguishes mathematical objects from physical objects by treating mathematical objects as abstractions. The examples he uses of mathematical, and not sensible, objects in that passage include line and figure. Given this, it seems that when Aristotle attends directly to lines, points, and figures in Physica V \& VI to distinguish continuity and contiguity this shows that the distinction he is working out applies, in his mind, both to pure and sensible magnitudes.

\footnotetext{
20 "But if this is admitted, that lines and points are substances more than bodies, but we do not see to what sort of bodies these could belong (for they cannot be in perceptible bodies), there can be no substance" (1002a15-19, emphasis mine).
} 
Further support for this can be found by comparing Aristotle's brief comments on continuity in Categoriae with his treatment of it in Physica. The properties which Aristotle ascribes to continuous things in the Physica passage are exactly the ones, with the exception of infinite divisibility, which he also explicitly ascribes to continuous quantities in his brief discussion of them in the Categoriae. In the treatment in Categoriae, being continuous serves to distinguish one of the two highest sub-genera of quantity from the other, qua quantity; in other words, the Categoriae remarks on continuity seems to be concerned with pure magnitudes rather than with sensible bodies. The primary aim in the Categoriae passage is to distinguish continuous from discrete quantities, rather than continuity from contiguity, so Aristotle's remarks there should perhaps not be taken as definitive. Still, since the infinite divisibility of continua plausibly follows from their parts having a certain spatial relation and sharing a common boundary, then all of the same distinctive properties are ascribed to continua in both works. I take it that this strengthens the comparison between them.

\section{$\S 3$ The problem for pure magnitudes}

If Aristotle has in mind both pure and sensible magnitudes when he expounds his notion of continuity, this raises the following difficulty, one whose solution, I think, illustrates how pure and sensible magnitudes are related in Aristotle's philosophy of mathematics. In Aristotle's analysis, contiguous magnitudes touch at some extremity while the boundaries at which continuous magnitudes touch actually become one (227a10-13). As was said above, the latter functions as his definition of continuity. Aristotle goes on to claim that magnitudes can be contiguous without thereby being continuous (227a21-23). This seems straightforwardly true when applied to bodies. But among pure geometrical magnitudes it appears as though contiguous magnitudes are continuous with each other just in virtue of their contiguity. That is to say, it seems at first as though there can be no merely contiguous pure magnitudes. If the boundaries of pure magnitudes touch, they also coincide, as I will show. But if they coincide, it is not clear how they can be distinguished from each other in order to show that they have not thereby become numerically one. If they cannot be distinguished, then any pure magnitudes which are contiguous are also 
continuous. This would contradict Aristotle's claim that "if there is contact, that alone does not imply continuity; for the extremities of things may be together without necessarily becoming one" (227a22-23).

Some examples should help to clarify. Consider as examples of contiguous sensible magnitudes two books side by side. Setting aside the fact that their covers may no longer be quite smooth, so that the surfaces which bound them do not quite touch along their length, it seems perfectly natural to think that they are contiguous. They are in succession, one standing next to the other with no other books in between, and their boundaries are touching on one side. Further, the cover of the first book is not the same as the cover of the second. They are numerically distinct, and it is because the surfaces are the boundaries of distinct bodies that they are not one. Because the boundaries are together without becoming one, on Aristotle's account the books are contiguous, but are not continuous with each other.

The question is whether the boundaries of any pure geometrical magnitudes, such as straight lines, figures, or solids, can touch or be together in place without thereby also becoming one. When their boundaries touch those boundaries coincide, and it is not clear how coincident boundaries (points, lines, or surfaces) can be distinguished from each other. To see why this is especially pressing for Aristotle, note that Aristotle sometimes uses the

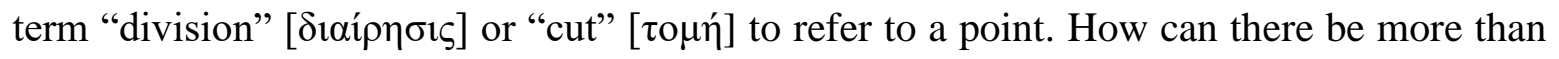
one division or cut in one place? If, as Michael White suggests (Continuous and Discrete,

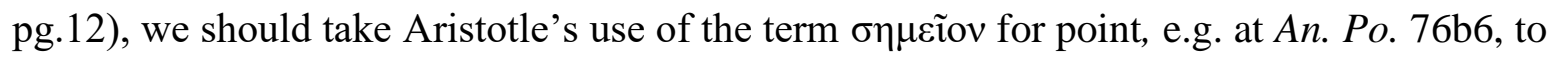
mean "place," the difficulty seems worse. Surely there could not be more than one place in a place. If not, then it appears as though when two mathematical boundaries touch, and so coincide, they become one. Perhaps pure magnitudes can only be continuous, and not contiguous.

Even Aristotle seems to think at times that the coincidence of boundaries is enough for their being one (cf. 231b4-5). According to Aristotle, points are indivisible and have no parts (Physica 231b1; cf. Euclid's Elements, Book I def. 1). Since they have no parts, points can only touch as whole to whole, all of the one touching all of the other (231b3). They cannot touch part to part, or even part to whole, since they have no parts. Further, they cannot be in succession (237b6-7), since between any two points is a line (cf. Euclid, Book 
I, postulate 1) and any line can be divided at some point on it. This is just to say that whenever two points are together and touch they coincide. ${ }^{21}$ Furthermore, Aristotle argues, when points do coincide, they are not distinct in the way that is required for them to be parts of continua, since the two coinciding points are not spatially separate [ $\tau$ ó $\pi \omega$ $\kappa \varepsilon \chi \omega \rho 1 \sigma \mu \varepsilon \dot{v} \alpha]$ (231b4-6). In other words, Aristotle's argument against points being parts of lines in 231b4-5 seems to be that points cannot be parts because when they touch they coincide, and when they coincide they are not numerically distinct from each other because they are not spatially distinct. Parts of continua, he says, are distinct from each other by being spatially separate, as I put it above, by being potentially numerically distinct items. When a continuum is divided up, the separated items, its erstwhile parts, can be set end to end contiguously, erstwhile part outside of erstwhile part. Thus if some or all of the parts of some continuous line were points, one should be able to set them all side by side, touching each other but distinct. When points touch, however, they are not spatially distinct. If spatial distinctnesss is what is required for the numerical distinctness of geometrical items, then coinciding points are not numerically distinct. It appears as though Aristotle holds that when two points coincide, there is really only one point.

This worry ramifies for the boundaries of two dimensional and three dimensional magnitudes. The basic thought is that the numerical distinctness of abstract geometrical items cannot be preserved if they coincide. Lines are contiguous when they are in succession and their boundaries touch, and the boundaries of lines are points. Since points become one when they coincide, lines become continuous when they are contiguous. By a similar reasoning it can be shown that contiguous two dimensional figures also form a continuum. The boundaries of two-dimensional figures are lines. In order for twodimensional figures to be contiguous without being continuous, it must be possible for them to touch each other, their boundaries being together in place, without their boundaries being one. When lines are together in place, however, they coincide and are not spatially distinct. Again, the analogous argument can be made, mutatis mutandis, for contiguous and continuous solids.

\footnotetext{
${ }^{21}$ Aristotle does seem to allow that points touch, not only in this passage but also in, for example, Metaphysica 1069a12.
} 
If boundaries' coinciding is sufficient for their becoming one it seems that pure magnitudes cannot be contiguous without also being continuous with each other. This would not only contradict Aristotle's claim to the opposite at (227a22-23), but it also indicates a difficulty for Aristotle's understanding of continuity as it might be applied by working geometers. Consider, for example, the kinds of diagrams relevant to Euclid's Elements. For example, in proposition I.10 in Euclid's Elements, the proof relies upon being able to distinguish two triangles for whom one of the sides is common. If contiguous figures are never merely contiguous but always thereby continuous, then Euclid's proof in I.10 would not work, nor would any geometrical proof which relies upon contiguous lines, figures, or solids.

If Aristotle's analysis of continuity and contiguity for pure magnitudes is to be saved, there must be a way to distinguish coinciding boundaries. I argue that items such as points and lines can be numerically distinct as boundaries, even when they are not spatially distinct and so cannot be proper parts of the magnitudes they bound. As was mentioned before, according to Aristotle boundaries are accidental beings which depend for their existence upon the things which they bound. Thus points, the boundaries of lines, are accidental beings individuated by the lines they bound. It might seem that the way to go to show that two lines are contiguous rather than potential parts of a continuous whole is to derive the numerical distinctness of the lines from the numerical distinctness of the points which are their boundaries. But if boundaries are accidental beings the distinctness of the points follows from and depends upon the individuation of the lines which they bound. The numerical distinctness of the lines, or of the magnitudes more generally, is what is fundamental. $^{22}$

\footnotetext{
${ }^{22}$ Marco Panza introduces a similar train of thought in a note, thus far unpublished, which he has written on Aristotelian continuity (2011, used with permission of the author). This piece was generously shared with me after the initial draft of this paper. Panza, himself taking a suggestion from Ross's commentary on Aristotle's Physica, argues that while two points coinciding are "thus the same thing in fact" (pg. 3), they are not "one" in the sense required for continuity unless they cannot be functionally distinguished (ibid). Ross puts it this way: "one thing, occupying one place, may be two things in the sense that it discharges two functions" (Ross, pg. 627). Ross himself rejects this interpretation of what Aristotle means when he says that continuity results when the boundaries become one. Taking up the suggestion Ross rejects, on Panza's reading, when two lines, $\mathrm{A}$ and $\mathrm{B}$, seem to share a point as a common boundary, they share the same point in the sense that the same location limits both lines. There is only one point, numerically. But the same point will also in a way be two, since it serves two functions; it serves to delimit A and also to delimit B.
} 
Aristotle takes up this strategy in his discussion of place in Physica IV. There is evidence within that discussion that Aristotle did not think that the coincidence of boundaries is, or is always, sufficient for the boundaries becoming one. At 211b10-14 Aristotle allows that the innermost boundary of the containing body and the boundary of the contained body coincide, but he argues that they are nevertheless not the same (211b13). The interesting thing for the discussion of contiguity and continuity is what Aristotle thinks grounds the numerical distinctness of these boundaries. Aristotle says that despite their coincidence they are not numerically one because they are the boundaries of different bodies. The numerical distinctness of the boundaries follows from the numerical distinctness of the bodies they bound. Thus for sensible magnitudes it is straightforwardly clear why coincident boundaries remain distinct. I suggest that for a similar reason Aristotle can consistently hold that coincident boundaries of pure magnitudes can be distinct. One must simply clarify what, for Aristotle, could ground the numerical distinctness of pure magnitudes.

In the case of sensible magnitudes the bodies can be distinguished by their physical characteristics. For example, one might be made of bronze while the other consists of water, or one body might be wooden while the other is a nail which has been nailed into the wood. The two bodies might be more fundamentally distinguished by being different compositions of form and matter. The difficulty for the discussion of geometry is that the sort of characteristics by which sensible magnitudes can be distinguished are abstracted from or, to adapt Lear's expression ${ }^{23}$, filtered out, by considering the magnitudes only qua geometrical. It is not clear what else could guarantee the distinctness of the pure

Because the same point is two in the sense that it serves two functions, delimiting A and delimiting $\mathrm{B}$, the whole line $\mathrm{A}+\mathrm{B}$ is actually divided and so is no longer continuous. If the point did not serve both functions then the line would not be actually divided, and would be one continuous line. If one takes it that what points are is given by their functions as limiting lines, then points can be functionally distinguished because of the way they are dependent beings, that is, all it is to be a point is to be the limit of (or to fulfill he function of limiting) a line. Panza's suggestion in this way may be consistent with my own. However, it seems consistent with Panza's characterization of points that the numerical distinctness of lines is founded upon the functional distinctness of points. Taken this way, Panza's suggestion is not consistent with the reading I have offered here, for I have argued that the numerical distinctness of points or indeed of any boundaries, depends upon the numerical distinctness of what they bound, rather than the reverse.

${ }^{23}$ Lear, Jonathan. 'Aristotle's Philosophy of Mathematics', The Philosophical Review, Vol. 91, No. 2 (Apr., 1982), pp. 161-192. 
magnitudes. If we cannot find an independent way of distinguishing the contiguous magnitudes, then we will not be able to use their numerical distinctness to get the numerical distinctness of their coincident boundaries. If we fail in this way, then we can no longer suppose that the two magnitudes are contiguous; they must be continuous. But we cannot then allow that they are [relational] continuous, as Aristotle has suggested, for [relational] continuity requires that we be able to distinguish the two lines as parts, or possible parts, of a single, unified whole. If we cannot distinguish the two lines, and so their coincident endpoints, then we cannot consistently accept Aristotle's understanding of the two kinds of continuity.

\section{$\S 4$ A solution which will not work}

Note that if I am correct that Aristotle intends his definitions of continuity and contiguity to apply to both abstract geometrical objects and to sensible magnitudes, this removes the possibility of White's understanding of the difference between continuity and contiguity for Aristotle. According to White, there is no purely mathematical distinction between contiguous magnitudes and continuous magnitudes: "Rather, continuity pertains to what is homeomerous, while contiguity pertains to parts which are spatially joined but essentially different" (The Continuous and the Discrete, pg. 27). Thus according to White, whether or not two magnitudes are continuous or contiguous depends on their nonmathematical properties. For example, if one of the "parts" of, say, a stretch of territory, is water while the other is land, the water and the land are contiguous. But if the territory contains no bodies of water and is all land, the parts are continuous. In Physica Aristotle concerns himself at times with abstract mathematical objects as I have argued, then his distinction between continuity and contiguity cannot be saved by appealing to sensible properties of sensible magnitudes in the way White suggests.

There is, I think further reason to set aside White's way of understanding Aristotle's distinction between continuity and contiguity, though perhaps not a full disproof. White's use of the term "homeomerous" is not quite in line with Aristotle's own use of the Greek

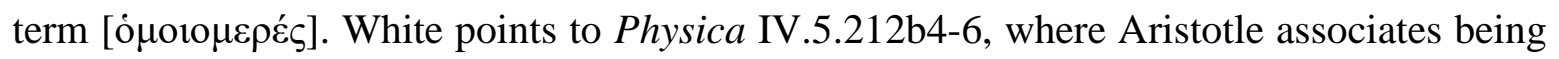
homeomerous with being continuous, to support his proposal that continuity is linked to 
homeomereity (The Continuous and the Discrete, footnote 31, pg. 27). I agree that for Aristotle continua are homoeomerous, yet I think that White's understanding of what this means for Aristotle is mistaken.

On White's reading the parts of continua must be homeomerous in the sense that they are of the same kind as each other: both water, in my example, or both land. On this definition the whole magnitude need not be thought of as being of that kind. It might, in my example, be a territory, or a farm, or something else. On White's reading the heteromereity of the parts of contiguous magnitudes consists in their being different from each other. Of course, in this case the whole magnitude of which they are parts cannot be of either kind. To reiterate, for White the sameness hinted at in the term "homeomerous" is between two things, in his examples, two parts of the same, as is the difference implied by "heteromerous". Yet in Aristotle's use of the term "homeomerous", it applies to wholes. The sameness implicated in the term is sameness of kind between the whole and its parts, rather than primarily between the parts. For example, in Metaphysica V Aristotle presents water as a homeomerous material, on the grounds that when it is divided into parts, its parts are also water. (1014a30-31). Aristotle uses the term ó this same way in Physica I.4 (187a25 and 188a13-15), when discussing Anaxagoras's view of the elements. For Aristotle, something is heteromerous when its parts are of a different kind than the whole from which they are divided. The way White is taking the term "homeomerous", an object could be heteromerous in Aristotle's use of the term as I have explained it, while the parts could be homoiomerous in the way White uses the term, for the parts could be of the same kind as each other, but different in kind from the whole.

If we understand homeomereity for Aristotle as consisting in the parts being of the same kind as the whole, then it will follow that for Aristotle continua are homeomerous. But their homeomereity will consist in their being of the same number of dimensions as the whole of which they are parts, rather than their having the same non-mathematical properties. This is because the proper parts of mathematical continua must be spatially separate, and potentially distinct mathematical objects. One can see this by realizing again that points are not, for Aristotle, parts of lines but termini; similarly, lines are not parts of figures but their boundaries. Proper parts of lines are always lines, and of figures always figures. 
Still, in one way White, and Berryman, who agrees with him in part about the relation between continuity and homeomereity ${ }^{24}$, are in agreement with the understanding of continuity and contiguity I have presented here. For sensible magnitudes, their boundaries will be coincident but not become one when the two sensible magnitudes are distinct bodies. For non-living bodies, this will most often be the case when the two bodies are of different kinds. My computer, for example, is contiguous rather than continuous with my wooden desk, though my desk's wooden legs are continuous with it. The touching boundaries of the two sensible magnitudes, my computer and my desk, are distinct from each other despite their coincidence, for the bodies which they bound are distinct. On my view, however, we still must discover what could make pure magnitudes, Aristotle's abstract mathematicals, distinct, since they do not have sensible properties which could distinguish them in the same way as sensible magnitudes are distinguished.

\section{$\S 5$ Complications with some proposed exegeses of Aristotle's mathematical ontology}

This puzzle narrows the field of views of mathematical ontology which Aristotle can consistently hold. To argue this, I will not be attending directly to the complex texts of Physica B.2 and Metaphysica M \& N, as so many capable scholars already have. It may be that Aristotle does hold some view of the nature of mathematical and geometrical objects which is inconsistent with his positing a difference between contiguity and continuity for geometrical objects in the way I have suggested. Perhaps all I accomplish here is pointing out a flaw in Aristotle's approach to geometry and mathematical ontology. Still, there are detailed readings of the relevant texts on offer which impute to Aristotle a view about mathematical ontology which will save his understanding of continuity and contiguity. I suggest that Jonathan Lear in his (1982) "Aristotle's Philosophy of Math", and Phil Corkum in his (2012) “Aristotle on Mathematical Truth" offer such readings. On the other hand, the view which Julia Annas presents in her (1976) introduction to the Clarendon series' Aristotle's Metaphysica Book $M$ and $N$ does not, and neither does Ian Mueller's

\footnotetext{
${ }^{24}$ Berryman, Sylvia. "Continuity and Coherence in Early Peripatetic Texts," in Eudemus of Rhodes, ed. István Bodnár, William W. Fortenbaugh. Rutgers University Studies in Classical Humanities, XI, New Brunswick, Transaction Publishers (2002): pg. 160.
} 
(1970) "Aristotle on Geometrical Objects" for similar reasons. This is not an exhaustive list of exegeses of Aristotle's mathematical ontology. However, by focusing on these I hope to highlight what sort of feature is required in order to save Aristotle's discussion of contiguity and continuity.

To begin with, let me provide an example by considering what mathematical platonism could offer to Aristotle in the fix he is in. By "mathematical platonism" I do not mean Plato's own views about mathematical ontology, at least not in all their details, but rather what is in common between Plato's views and what a present day philosopher of mathematics would understand by the term. This is, in Julia Annas's words,

a type of realism, amounting to the belief that mathematical objects such as numbers literally exist, independent of us and our thought about them. Numbers are not, of course, in the world around us; they do not exist in space and time. But they exist none the less; they are there to be discovered before we think of the means of describing them. $(M \& N, \text { pg. 3-4 })^{25}$

It is, of course, well-established that Aristotle did not follow his mentor's lead by proposing such an ontology.Annas, for example, commenting on the tone and general intent of Aristotle's remarks on philosophy of mathematics in Metaphysica M \& N, says that "Aristotle's attitude is best characterized as 'anti-platonism"” ( $M \& N, \mathrm{pg}$. 26), since the bulk of his treatment there is polemical against various kinds of platonism he finds in the Academy. Further, Aristotle seems to more generally hold, contrary to Plato, that material particulars are ontologically prior to the properties they possess ${ }^{26}$; it would be odd, to say the least, if mathematical properties were an exception to this.

Setting this aside, however, suppose Aristotle were to be a platonist about mathematical objects: would this enable him to preserve the numerical difference between two supposedly contiguous lines? I think not. To see this, consider the problem which Julia

${ }^{25}$ Cf. Mueller (1970), pg. 156. Similarly, Mark Balaguer, in his article for the SEP entitled "Platonism in Metaphysica", in its subsection on platonism in mathematics proposes that mathematical platonism holds that the truths of mathematics are about "about abstract objects rather than mental or physical objects of some kind" (https://plato.stanford.edu/entries/platonism/\#4.1). Platonism about mathematical objects, according to Oystein Linnebo, "is the Metaphysical view that there are abstract mathematical objects whose existence is independent of us and our language, thought, and practices" (https://plato.stanford.edu/entries/platonism-mathematics/).

${ }^{26}$ There are complexities to this general characterization of Aristotle's Metaphysical views, leading to well-entrenched debates regarding, for example, Aristotle's treatment of form as substance-of-asubstance in Metaphysica Z. 
Annas calls the "Uniqueness Problem". Annas suggests that this problem motivates positing geometrical intermediates such as are thought by some to be a part of the "unwritten doctrines" of Plato. The Uniqueness Problem is as follows:

A theorem mentions two circles intersecting. What is referred to cannot be the circles drawn in the diagram (cf. the Euthydemus passage), for these may fail to give the needed result through careless drawing or the like. But nor can it be the Form of Circle suggested (carelessly) in the Philebus, for that is unique. $(M \& N, \text { pg. } 25)^{27}$

If there is only the Form of Line, then there cannot be two contiguous lines any more than there could be two contiguous circles in Annas's example, or two of any Form. Contiguity, whatever it is, could therefore not belong to geometrical objects in their own right; it could only belong to physical bodies in their particular instantiations of the Forms.

Even if one avoids the Uniqueness Problem, so that it is possible for there to be two lines, we can discover a further, related difficulty through the following sort of thought experiment. If we try to conceive of a line divided at a single point into two parts which share that point as an endpoint, there is still nothing in our simple theory of mathematical ontology which provides the criteria according to which the supposed contiguous lines can be distinguished as mathematical items. That there could be two lines in some case in mathematics does not help the case where the supposedly distinct lines have coincident endpoints; there is nothing to distinguish the two lines which comes from their properties as lines. Even positing that they are distinct because one is on the left-hand side and the other on the right-hand, for example, presumes that they are distinct to begin with so that they can have position relative to each other. What seems to distinguish the two lines, if anything, is our imagination, our way of looking at things. If this is correct, then contiguity as a mathematical property is in an important way mind-dependent. This, however, is not consistent with mathematical platonism.

Setting aside mathematical platonism, prominent readings of Aristotle fail to solve the contiguity problem for similar reasons. Ian Mueller in his (1970) article offers a subtle view according to which Aristotle takes geometrical objects to be "substance-like

\footnotetext{
${ }^{27}$ Mueller points to a similar problem in his "Aristotle on Geometrical Objects", pg. 163, as quoted on my page 16.
} 
individuals with a special matter - intelligible matter” (“Geometrical Objects”, pg. 164). He motivates his view first by proposing that there are two ways to think about abstraction:

If abstraction is primarily thought of as eliminating properties, one will think of mathematical objects as physical objects looked at as if they did not have certain properties. On the other hand, if one thinks of abstraction primarily as eliminating matter, one will think of mathematical objects as properties like roundness and triangularity. ("Geometrical Objects", pg. 161-162)

Mueller takes the second view; mathematical objects are in some sense universals, properties which are separated from matter. He does point out a problem for universals which is very similar to the one Annas called the Uniqueness Problem, which he characterizes thus: "First of all, universals do not have exactitude of the kind which Aristotle attributes to mathematical objects. Circularity does not touch straightness in a point or in any other way" (“Aristotle on Geometrical Objects”, pg. 163). Yet he proposes that the subtleties of Aristotle's view enable him to avoid this, and related, difficulties.

According to Mueller, Aristotle takes the basic mathematical properties to be extension in one, two, or three dimensions, or "the purely dimensional underlying other properties" (pg. 166). These basic properties are indefinite extension, and they are general, in the sense that circles and rectangles are species of plane figures, and cubes and spheres of solids (three-dimensional extension). Mueller relies on Alexander, the author of In Metaphysica, for the comment that genera are intelligible matter (pg. 167, note 34). According to Mueller, these most basic geometrical properties of bodies serve as intelligible matter for geometric properties, the differentiae of the genera, such as straight or curved, three-sided or two-sided. The objects which geometers study are thus complexes of noetic or intelligible matter, i.e., the basic mathematical properties of physical things, and other geometrical properties. Though Mueller does not state this explicitly, he presents this hylomorphic kind of composition of geometrical objects as providing them with the kind of particularity required for them to be fitting subjects of study for geometers. By being substance-like in this way, geometrical objects can be particular, and, he implies, have the requisite kind of exactitude.

I think that this puts Mueller in the same position as the platonist I mentioned above. Mueller's understanding of mathematical objects as being substance-like shows that mathematical objects such as lines and triangles are not unique (there can be more than one 
line in the cosmos, or more than one triangle, apart from the lines and figures found imperfectly in physical bodies), but he still has provided no resource for distinguishing our ersatz contiguous lines from each other. Straight and curved, for example, the differentiae of one-dimensional extension, do not distinguish the ersatz lines.Nor can we distinguish them by the ratio of their lengths without circularly assuming that they are distinct. We could imagine that they are separated, then brought together; but motion is not a part of geometry. All that is left to distinguish them is our imagination. What makes them contiguous, then, is not their geometrical relation to each other (since, not being distinct in themselves, they can have no relation to each other), but how we choose to think of them or imagine them.

Julia Annas regards Mueller's reading of Aristotle's mathematical ontology as an "attractive, <...> a systematic and a well-thought-out account" (ibid), a "coherent scheme" of geometrical ontology (pg. 31). She criticizes it only on the grounds that it is not wellsupported by the text. I have argued on the contrary that, whatever its internal merits as an ontology, the geometrical ontology Mueller ascribes to Aristotle is not, in fact, coherent with Aristotle's treatment of mathematical continuity and contiguity.

Annas proposes a reading very similar to Mueller's, though she understands Aristotelian abstraction somewhat differently. On her view abstraction is "(deliberate) lack of attention" (pg. 32), which, in the case of geometrical abstraction, seems to be inattention to all the sensible or non-geometrical features of a thing. ${ }^{28}$ Since she hesitates to ascribe to Aristotle Mueller's subtle reading of “intelligible matter", she argues that Aristotle's abstractionism is vulnerable to the kind of objection Frege made to abstractionists in his own time; in particular, Annas's Aristotle is vulnerable to a version of the Uniqueness Problem. Annas presents this version as being concerned with the impossibility of identifying any abstract object. Thus it is not quite the same as the difficulty which I emphasized before, the impossibility of there being more than one of each kind of mathematical object, but the difficulty ramifies. The problem, she says, quoting Frege, is that "we thus obtain from each object a something wholly deprived of content; but the

\footnotetext{
${ }^{28}$ Cf. Mueller pg. 160, where he argues that Aristotle thinks of mathematical abstraction as more than "eliminating something from consideration," though it no doubt involves this.
} 
something obtained from one object is different from the something obtained from another object - though it is not easy to say how" ( $M \& N$, pg. 33).

To see the difficulty for Aristotle on this view, suppose that the purportedly contiguous lines are abstracted from two contiguous bodies. The bodies themselves were two in number, so one hopes that the objects abstracted from them, the lines, will also be two. On Annas's reading, as on Mueller's, Aristotle holds that geometrical abstraction produces a new object. As a result of the abstraction, one does not have the original object viewed in a certain way, but instead a new abstracted object. Yet if abstraction consists in ignoring every non-mathematical feature of the original body, the worry is that one will thereby separate the abstracted objects, even if only in thought, from any features which could distinguish them. Thus there seems to be no reason to take the supposedly contiguous two lines as being, in fact, two, apart from their history as the results of abstraction from two different bodies. Yet this is a feature of how we approach or grasp them, rather than a feature of the geometrical objects themselves. In other words, if this is the way Aristotle understands geometrical objects as abstractions, then he has no grounds for distinguishing contiguity from [relational] continuity, nor any coherent picture of the two kinds of continuity.

Annas proposes that Aristotle's view of geometrical objects is otherwise consistent $^{29}$; it is just not a very good view, since it is prone to Fregean objections. I think she is correct about the problem such a view faces. But I think that because of this the view is also inconsistent with Aristotle's treatment of continuity, for the reasons already stated. It cannot solve Aristotle's puzzle, so that continuity and contiguity of the kind he defines is impossible given his ontology. If the view Annas describes is in fact Aristotle's view, then he has erred doubly. Yet inconsistency is a charge not lightly to be laid against Aristotle,

\footnotetext{
${ }^{29}$ She does point out that Aristotle suggests that in arithmetic numerical properties are abstracted, while in geometry geometrical objects are abstracted (pg. 31-32). It is difficult to know what to make of this apparent inconsistency, unless one follows Mueller in thinking that the difference between properties and objects is not very important when it comes to the results of mathematical abstraction (Mueller, pg. 166). If Aristotle accepts a mathematical ontology such as Lear's or Corkum's, there is even more reason to think this; both discrete and [nonrelational]continuous magnitudes, i.e., numbers and geometricals, are properties strictly speaking, though a mathematician may be licensed to treat them as objects in the context of her study.
} 
and there are at least two ways of understanding Aristotle's mathematical ontology which avoid attributing this inconsistency to him. To these I turn next.

\section{$\S 6$ Continuity and Aristotle's mathematical ontology}

The two readings of Aristotle's mathematical ontology offered by Jonathan Lear and Phil Corkum, respectively, share a common feature which offers to Aristotle a way to preserve his understanding of the two kinds of continuity. The common feature is that both emphasize the way in which geometrical objects are dependent beings, and clarify what this means for their status as abstractions. They both explain the way in which mathematical objects depend for their existence on the bodies from which they are abstracted so as to avoid the Fregean worry Annas presents. On both views, geometrical objects are dependent on physical bodies so that it is part of what they are to be dependent on some particular body; thus their identity as well as their existence is grounded in the object from which they are abstracted. Further, since for neither of these scholars does abstraction consist simply in inattention toward certain features of a body, the identity of a geometrical object is preserved.

Both propose that, according to Aristotle, there is a sort of fictionalism involved in the way that mathematicians treat geometrical objects. According to Jonathan Lear, the fictionalism of Aristotle's philosophy of math consists in the way in which one "filters" out non-mathematical properties of some body so as to treat it as being merely mathematical. Lear says the following:

Generalizing, one might say that Aristotle is introducing an as-operator, or qua-operator, which works as follows. Let b be an Aristotelian substance and let "b qua F" signify that b is being considered as an $\mathrm{F}$. Then a property is said to be true of $\mathrm{b}$ qua $\mathrm{F}$ if and only if $\mathrm{b}$ is an $\mathrm{F}$ and its having that property follows of necessity from its being an $\mathrm{F}$ :

$\mathrm{G}(\mathrm{b}$ qua $\mathrm{F}) \leftrightarrow \rightarrow \mathrm{F}(\mathrm{b}) \&(\mathrm{~F}(\mathrm{x})-\mathrm{G}(\mathrm{x}))$.

Thus to use the qua-operator is to place ourselves behind a veil of ignorance: we allow ourselves to know only that $\mathrm{b}$ is $\mathrm{F}$ and then determine on the basis of that knowledge alone what other properties must hold of it. (pg. 168)

Lear claims that "in geometry $<\ldots>$ one is really only considering an actual physical object in abstraction from its particular physical instantiation" (pg. 172). Lear thus 
understands abstraction according to the first way Mueller proposed, so that as a result of abstraction one takes one's object to be the original thing on which the abstraction was performed, though considered in some particular respect. Still, a geometer accepts the fiction that there are pure geometrical objects, objects which are simply triangles, for example, and not triangular bodies, in order to focus on the properties the body has because it is triangular. According to Lear, geometry studies sensible magnitudes, but it attends to them only insofar as they have magnitude or are geometrical, not insofar as they are material, sensible, etc. Within the study of geometry one applies what Lear called a "predicate filter" (Lear, pg. 168 -169) to attend only to those properties which follow from the object being extended and shaped:

Thus, for Aristotle, one can say truly that separable objects and mathematical objects exist, but all this statement amounts to - when properly analyzed - is that mathematical properties are truly instantiated in physical objects ${ }^{30}$ and, by applying a predicate filter, we can consider these objects as solely instantiating the appropriate properties. (Lear, pg. 170)

Thus if we take Lear's suggestion about how to understand Aristotle's mathematical ontology, the bodies which we, as geometers, are examining mathematically are themselves distinct, so that their mathematical properties are differentiated by the bodies they belong to. ${ }^{31}$ If we begin our geometrizing with, for example, two figures $\mathrm{X}$ and $\mathrm{Y}$, which are numerically two because they are instantiated in distinct bodies, nothing about our geometrical analysis of these should change the fact that they are two, that is, many and not one. Given Lear's emphasis that the pure magnitudes really are just the sensible bodies, there is no reason to give up on the numerically distinct identities of the pure magnitudes arrived at by abstraction, even within the fiction. If you start off with two contiguous bodies, as a result of your abstraction you will thus have two solids, and thus two surfaces, and thus two contiguous lines. Thus the mathematical ontology which Lear finds in Aristotle is consistent with Aristotle's account of continuity.

According to Corkum, "in Aristotle's view, the fiction of mathematics is not to treat what does not exist as if existing but to treat mathematical objects with an ontological

\footnotetext{
${ }^{30}$ Emphasis mine.

${ }^{31}$ Admittedly this touches upon the discussion of Aristotelian non-substantial particulars. Here I presuppose that non-substantial particulars are non-recurrent. For a recent defense of this position, see Wedin (2000), Erginel (2004), or Devereux (1992).
} 
status they lack” (“Aristotle on Mathematical Truth,” pg. 1061). On Lear's reading, the interpreter might continue to use the expressions "pure magnitudes" and "sensible magnitudes", with the proviso that there are not really any pure magnitudes; the do not exist, but are a fiction. On Corkum's reading, there really are pure magnitudes, it is just that these are ontologically dependent beings. In ignoring what they depend on the geometer is thus engaging in a sort of fictionalizing, but it is not by pretending that there are pure magnitudes.

As Corkum reads Aristotle, mathematical objects, the items I have been calling "pure magnitudes", "possess their ontological status in virtue of standing in some relation to sensible substances" (pg. 1071), so that "Aristotle holds that mathematics treats what exists qualifiedly as if it exists unqualifiedly" (pg. 1072). Thus, for example, a geometer might treat two lines as if they can stand alone, as if their status as existing, and as being the particular existent that they are, does not require any other being. In reality this is not the case; any particular line, for example, depends for its existence on the body whose surface it bounds. Now, while Corkum's claim that for Aristotle mathematical objects are ontologically dependent is consistent with my proposal in this paper, the suggestion that in mathematics we treat mathematical objects as though they are independent seems to be in tension with it. How can we ground the numerical distinctness of our mathematical continua in the bodies they are properties of if we are treating them in mathematics as though they are not properties, that is, not ontologically dependent?

The answer I have in mind is related to Aristotle's methodological criticism of Parmenides in Physica I. In Physica I.2 Aristotle says that "to investigate whether what exists is one and motionless is not a contribution to the science of nature. For just as the geometer has nothing more to say to one who denies the principles of his science-this being a question for a different science or for one common to all — so a man investigating principles cannot argue in the way mentioned" (184b25-185a3). Aristotle's subject in Physica $\mathrm{I}$ is the principles of natural science. By the end of Physica $\mathrm{I}$ it is clear that Aristotle takes change to be among the principles. This is partly explained by his claim in Physica II that the subject of natural science itself is what changes from an internal principle; it stands to reason that one must be able to make sense of change to make sense of changing things. In I.2 Aristotle seems to be criticizing Parmenides and Melissus for 
denying the subject of his current investigation; it does not help one investigating principles to deny that there are any, and doing so is no part of that investigation. For the same reason, I take it, denying or questioning the existence of the subject of any scientific investigation is no contribution to that science. In the case of the study of the principles of natural science, one cannot contribute to it by denying that there is such a thing as change. In the case of natural science itself, one cannot contribute to it by questioning or denying the existence of the world of a multitude of changing things. A similar argument applies to the present question. If one starts off one's investigation with two mathematical figures, ontologically dependent on two sensible bodies, it is no contribution to the inquiry into their mathematical properties and relations to deny that there are two. If you start with two mathematical objects, having begun more fundamentally with two sensible objects, you will not end up with only one mathematical object once you start doing geometry.

\section{Conclusion}

In summary, the thought that coincident boundaries are numerically distinct because they are dependent bodies rather than spatially distinct helps to explain how it is that when two magnitudes are [relational] continuous with each other they form a [non-relational] continuum. When magnitudes are [relational] continuous their boundaries become one. When the boundaries become one there could be either only one point bounding both lines, or one point bounding only one line, or one bounding neither. It cannot be that one point bounds both lines, since points are individuated by the lines they bound. But it also cannot be the case that only one of the lines is bounded, since for Aristotle all lines are actually finite and bounded (there are no open line segments). But if the one point bounds neither line then it no longer marks an actual division between magnitudes. At best it marks a place where there could be a division - the point is only potential. When the boundaries of magnitudes become one in the way required, they disappear as actual boundaries, so that they, and the parts they delimit, are merely potential. Thus when two magnitudes are [relational] continuous, they form (potential) parts of a single continuous whole. ${ }^{32}$

\footnotetext{
${ }^{32}$ It is for this reason that I find Bostock's claim (Bostock, pg. 183) that a continuuggm, according to Aristotle is "such that any two parts into which it is divided must share a limit" at best
} 
On my reading, the same distinction which holds for continuous and contiguous bodies holds also for continuous and contiguous mathematicals, or pure magnitudes. A continuous whole, whether a body or a purely geometrical item, is an undivided per se unity which has parts only potentially. Its parts, such as they are, are continuous with each other. They are such that their boundaries have become one, no longer actually but only potentially distinguishing them. Nevertheless, if the parts are made actual, the continuum being destroyed, the parts would be actually numerically distinct magnitudes, marked off from each other by their erstwhile shared boundary. Thus a continuum is such that when successive parts are actualized they bear toward each other the relation of contiguity.

A mathematical ontology such as Lear or Corkum offers enables contiguous pure magnitudes such as lines, figures, and solids, to be distinct despite their coincident boundary points. If one begins with two bodies, one thus has two solids. Then, if one is focusing on just one side, one thus has two distinct figures despite their touching boundaries. And if one focuses on the boundaries where the figures coincide one will still have two lines. The lines are the boundaries of the figures, thus since the figures are numerically distinct, so, too, are their boundaries. Similarly, if one attends to the lines on the figures which touch at a point rather than along their length. Because the lines are parts of distinct figures, which are ultimately parts of distinct solids, which are finally ontologically dependent on distinct bodies, the coinciding endpoints of the lines are also distinct.

Keren Wilson Shatalov

Illinois Intitute of Technology

ambiguous. On my reading, as potential parts the spatial parts of a continuum do share a limit; but when they are parts in this way the continuum is not actually (yet) divided. To point out such parts is merely to show where the continuum could be divided. Once the continuum is divided, however, the parts do not share a boundary; they are merely contiguous, where this means that their boundaries touch without becoming one. Further, once the continuum is divided the magnitudes which result are no longer properly speaking parts of a continuum. 


\section{Bibliography}

Annas, Julia. “Aristotle, Number, and Time.” The Philosophical Quarterly, Vol. 25, No. 99 (Apr., 1975): 97-113

Annas, Julia. Aristotle's Metaphysica Book M and N. Oxford, Clarendon Press (1976)

Berryman, Sylvia. "Continuity and Coherence in Early Peripatetic Texts," in Eudemus of Rhodes, ed. István Bodnár, William W. Fortenbaugh. Rutgers University Studies in Classical Humanities, XI. New Brunswick, Transaction Publishers (2002): 157-169

Bostock, David (1991) 'Aristotle on Continuity in Physica VI', in L. Judson, ed., Aristotle's Physica: A Collection of Essays, (Oxford: Clarendon Press), 179-212

Corkum, Phil. "Aristotle on Mathematical Truth." British Journal for the History of Philosophy, Vol. 20, No. 6 (Oct. 2012): pp. 1057-1076

Corkum, Phil. “Aristotle on Ontological Dependence”. Phronesis, Vol. 53, No. 1 (2008), pp. 65-92

Dedekind, Richard. "Continuity and Irrational Numbers," in Essays on the Theory of Numbers, trans. Wooster Woodruff Beman. New York, Dover Publications, Inc. (1963)

Euclid. Elements, trans. Sir Thomas L. Heath, in Great Books, Vol. 11, ed. Robert Maynard Hutchins. Chicago, Encyclopaedia Britannica, Inc. (1952)

Furley, David. "The Greek Commentators' Treatment of Aristotle's Theory of the Continuous," in Infinity and Continuity in Ancient and Medieval Thought, ed. Norman Kretzmann. Ithaca, Cornell University Press (1982): 17-36

Kretzmann, Norman, Ed. Appendix A, in Infinity and Continuity in Antiquity and the Middle Ages, Cornell UP (1982): pp. 309-321

Lear, Jonathan. "Aristotelian Infinity." Proceedings of the Aristotelian Society, New Series, Vol. 80 (1979 - 1980): 187-210

Lear, Jonathan. "Aristotle's Philosophy of Mathematics." The Philosophical Review, Vol. 91, No. 2 (Apr., 1982): 161-192

Mendell, Henry, "Aristotle and Mathematics", The Stanford Encyclopedia of Philosophy (Winter 2008 Edition), Edward N. Zalta (ed.), URL <http://plato.stanford.edu/archives/win2008/entries/ aristotle-mathematics/>.

Mueller, Ian. "Aristotle on Geometry.” Archiv für Geschichte der Philosophie, vol. 52 (1970): 156171

Miller, Fred. "Aristotle against the Atomists", in Norman Kretzmann ed., Infinity and Continuity in Antiquity and the Middle Ages, Cornell UP (1982): 87-111

Panza, Marco. 'Aristotle's Continuity.' Unpublished. Nov. 2011. Used with permission from the author.

Ross, David. Aristotle's Physica. Oxford, Clarendon Press (1936)

Studtmann, Paul. “Aristotle's Category of Quantity: A Unified Interpretation.” Apeiron: A Journal for Ancient Philosophy and Science, Vol. 37, No. 1 (March 2004): 69-91

Wedin, Michael. Aristotle's Theory of Substance: The Categoriae and Metaphysica Zeta. Oxford, Oxford University Press (2000)

White, Michael J. The Continuous and The Discrete. Oxford, Clarendon Press: 1992. 